\title{
Effect of glucose oxidase addition on the textural characteristics of wheat-maize dough and bread
}

\author{
Jean Didier KOUASSI-KOFFI ${ }^{1,2}$, Alina STURZA ${ }^{1}$, Adriana PĂUCEAN ${ }^{1}$, Simona MAN ${ }^{1}$, Andruța Elena MUREȘAN ${ }^{1}$, \\ Georgiana PETRUT, ${ }^{1}$, Vlad MUREȘAN ${ }^{1 *}$, Sevastița MUSTE ${ }^{1}$
}

\begin{abstract}
The aim of this study was to assess the effect of adding glucose oxidase (GOX) on wheat-maize dough and bread textural characteristics. It strengthens the importance and need of replacing wheat flour with maize flour in regions where extensive cultivation of wheat is not possible. For improving the rheological properties of bread, GOX was added to wheat and wheat-maize flours. Wheat and maize flours were used in several ratios, but the best results were obtained for (on flour basis): 80:20, 75:25, 70:30, where the highest values correspond to the wheat flour. Wheat-maize dough and bread volume were slightly influenced by GOX addition. Dough strength was higher in the case of dough without GOX addition than the samples enriched by GOX, while crumb strength of GOX enriched maize bread was higher than the samples without GOX. The obtained data might be useful for future studies, while it was demonstrated here the effect of GOX addition on wheat-maize dough and bread.
\end{abstract}

Keywords: dough rheology; bread freshness and hardening; glucose oxidase; maize flour.

Practical Application: Enhanced wheat-maize bread for countries where extensive wheat cultivation is not possible.

\section{Introduction}

Bread is one of the oldest and popular foods of mankind, being a good source of calories. This product is obtained mainly from wheat flour, water, yeast and salt (Dewettinck et al., 2008), but not all geographic areas allow the extensive cultivation of wheat, because of climate, soil etc. Among the cereal flours, only wheat flour forms viscoelastic dough when mixed with water. The viscoelasticity is determined by gluten proteins which are water compatible and thus, swell and interact. The gluten protein network develops and sets generally in wheat-based food. The nonlinear viscoelastic behavior of wheat flour dough is mainly due to the continuous gluten matrix and starch granules embedded in it. It has typical properties of both solid and liquid bodies, and an intermediary rheological behavior between the ideal solid and fluid bodies. Therefore, an accurate characterization of the dough requires rheological measurements (Banu et al., 2011).

The functional properties of bread dough greatly depend on the proteins forming the gluten network (Caballero et al., 2005). Prominent reactions include sulfhydryl (SH) oxidation and SH-disulfide (SS) interchange, which lead to SS cross-links. Other covalent bonds are also formed. The type of protein being cross-linked appears to be more important than the type of cross-link formed and it is highly correlated with the character of qualitative changes in the final product. The HMW (high molecular weight) glutenin subunits are correlated with the strength of gluten network and the bread volume, while albumins and globulins are more important for textural and crumb grain properties (Caballero et al., 2005).

During baking, starch gelatinisation and pasting and heat-setting of gluten proteins occur, resulting in the typical solid foam structure of baked bread (Sievert et al., 2007; Steffolani et al., 2012). These unique properties account for wheat, which is cultivated in large quantities throughout the world (Day et al., 2006). Although, the knowledge about its chemistry and rheology has expanded enormously during last decades, the reactions responsible for the dough and gluten formation are still challenging.

Maize is the main cereal grain as measured by production, but ranks third as a staple food after wheat and rice (Gwirtz \& Garcia-Casal, 2014). The maize flour is gluten free and can be used in bakery as a low-priced, nutritive and tasty additive (Bilgiçli et al., 2006); in United States of America and other countries (Canada, France, Germany, England, Spain), different types of maize are used in bread making, animal feed, fuel and beverage (e.g. ethanol production) (Rose et al., 2010).

Enzymes are used in bread making for optimizing different quality aspects of bread (Steffolani et al., 2010). Glucose oxidase (GOX) ( $\beta$-D-glucose: oxygen: 1-oxidoreductaze; EC 1.1.3.4.) is an enzyme obtained from different fungal sources, mainly from Aspergillus niger (Singh \& Verma, 2013; Kerman et al., 2014). GOX is used for many industrial applications: in baking, dry

${ }^{1}$ Food Engineering Department, Faculty of Food Science and Technology, University of Agricultural Sciences and Veterinary Medicine Cluj-Napoca, Cluj, Romania

${ }^{2}$ Unité de Formation et de Recherche en Science et Technologie des Aliments, Université Nangui Abrogoua, Abidjan, Côte d'Ivoire

*Corresponding author: vlad.muresan@usamvcluj.ro 
egg powder production, wine, gluconic acid production, etc. (Wong et al., 2008), being generally recognized as safe (GRAS) under Food and Drug Administration (FDA) classification (Food and Drug Administration, 2002).

Various oxidizing agents are used into bakery formulations where the gluten network is too weak to exert its optimum activity; therefore, one of its purposes is to strengthen gluten, thereby, improving the bread's final volume and texture (Decamps et al., 2012). Traditionally, potassium bromate $\left(\mathrm{KBrO}_{3}\right)$ was used (Figoni, 2003), but its use has been banned in many countries after being recognized as a carcinogen (Moore \& Chen, 2006). Nowadays, a safe alternative such as GOX is used in bakery (Hanft \& Koehler, 2006; Bonet et al., 2006); it is an effective oxidant to produce bread with improved texture and increased loaf volume (Vemulapalli et al., 1998; Rasiah et al., 2005). In the meantime, GOX is known to cause cross-linking of dough protein (Rasiah et al., 2005) and exerts effects such as reducing the sulfhydryl content as well as increasing viscosity in the water soluble portion of dough (Vemulapalli \& Hoseney, 1998). Consequently, the aim of this study was to assess the effect of adding glucose oxidase on wheat-maize dough and bread textural characteristics. To reach to this objective, GOX was added to the bread dough in order to improve its rheological properties, while maize flour addition ranged from $20 \%$ to $30 \%$; the optimum level of maize flour addition being also tested.

\section{Materials and methods}

\subsection{Materials}

All-purpose wheat flour (type 550) variety "Apache" obtained from Boromir Group (Romania) was used without any chemical or proteins supplementation (12.3 wt \% water, $11.6 \mathrm{wt} \%$ proteins and $0.58 \mathrm{wt} \%$ ash (moist basis). White maize flour sweet variety was obtained from a local market in Abidjan, South-western Ivory Coast, also without any supplementation. Flours were stored in a freezer at $-20{ }^{\circ} \mathrm{C}$ for 7 days and then at $4{ }^{\circ} \mathrm{C}$ for 1 to 3 days before use. Glucose oxidase (GOX, $10000 \mathrm{GU} / \mathrm{g}$ ) was procured from Enzymes \& Derivates, Neamt, Romania. The ingredients were weighted and placed in sealed boxes in a refrigerator at $4{ }^{\circ} \mathrm{C}$ during the night before the test.

Wheat dough containing $20 \%$ of maize ('WMD20\%') is the wheat dough with $20 \%$ of maize flour; a similar sample name was given to the samples with $25 \%$ and $30 \%$ of maize content. On the other hand, when Glucose Oxidase (GOX) was used, the wheat dough containing $20 \%$ of maize and the enzyme was coded 'WMD20\%+GOX', similar sample name being used for all maize flour ratios. For bread samples, 'WBD20\%' was the bread obtained from dough sample 'WMD20\%', while 'WBD20\%+GOX' is the bread obtained from the dough sample 'WMD20\%+GOX', similar sampling design being applied for all bread samples.

\subsection{Dough molding, fermentation and baking}

Dough formula (flour basis) consisted of $2.0 \mathrm{wt} \%$ salt, 1.62 wt \% glucose, 51.96 wt \% water (added water), 5 nkatal $/ g$ of GOX (only for GOX enriched dough/bread, it could be used 48 hours after preparation) and $3 \mathrm{wt} \%$ yeast, quantities of wheat and maize flour varied as is shown in abstract. Ingredients were mixed in the cuve of baking machine (ZBM0990X (43Z010), Zelmer, Poland) and kneaded $30 \mathrm{~min}$. After kneading, dough were removed, shaped manually into a cylindrical sample and placed in a fermentation tube. The hands were cleaned with sample flour for stickiness dough minimization on the skin during the shaping. The top of the tube was tightly closed with plastic cover and the edges were lubricated with paraffin oil. The tube with dough sample was placed in a fermentation oven at $25^{\circ} \mathrm{C}$. Cylindrical tube was already graduated, which ensured the dough fermentation level control. A cylindrical dough sample of $25 \pm 0.5 \mathrm{~g}$ was used. The molded dough was fermented for $100 \mathrm{~min}$. Measurements data were taken every $10 \mathrm{~min}$. This procedure was used for all types of dough (with/without GOX). The fermented dough was baked during 50 min at Basic regime Light program.

\subsection{Dough and bread texture analysis}

Dough hardness and freshness (dough fresh and stiff appearances) properties were determined by CT3 Texture Analyzer equipped with a $10 \mathrm{~kg}$ load cell (Brookfield Engineering Laboratories, Inc. USA). Equipment control and initial data handling were performed using TexturePro CT V1.5 Software (Brookfield Engineering Laboratories, Inc.) as the maximum force of the compression cycle. To the moving cross-head was attached a cylinder probe TA 4/1000 of $38.1 \mathrm{~mm}$ diameter. The dough samples were subjected to compression test under following conditions: $1 \mathrm{~mm} . \mathrm{s}^{-1}$ constant cross-head speed, $5 \mathrm{~g}$ trigger load and $70 \%$ maximum deformation in lubricated conditions. The dough disk was lubricated and then placed on the lubricated base plate of the CT3 Texture Analyzer. The lubricated upper plate was then placed in contact with the surface of the dough disk at a contact force no greater than $0.1 \mathrm{~N}$ but allowing contact between the upper plate and the entire surface of the lubricated dough disk. Paraffin oil ( $\eta=0.15$ Pa.s) was used as a lubricant according the conditions described by Secor et al. (1989) and Macosko (1994).

Bread freshness and hardness properties were determined by using the same equipment as mentioned for dough. A stainless steel knife was used to prepare cylindrical slices of bread $(25 \mathrm{~mm}$ of diameter and $52 \mathrm{~mm}$ of thickness). Each bread sample was then centered under cylinder probe (TA 4/1000; $38.1 \mathrm{~mm}$ diameter), being compressed under the same conditions as dough samples. The test was performed immediately after preparing the bread slices in order to avoid samples crumb drying.

\subsection{Bread weight and volume measurement}

Bread was obtained at end of the baking process. It was stored 2 hours at $25^{\circ} \mathrm{C}$ at $85 \%$ of humidity. It was then placed in an airtight plastic bag during 24 hours for its relaxation. Method of colza seeds was used to measure the volume of the bread (American Association of Cereal Chemists, 1998). The bread textural properties were performed after the storage period.

\subsection{Bread crumb physical properties}

Samples slices bread were cut in the parallel direction of its lifting into the oven during the baking process in order to preserve and protect their alveolar structure. Picture was 
taken with a photo flatbed (Epson ${ }^{\oplus}$ Perfection V370) covered with a black box to avoid the influence of the surrounding light. This device provided good contrast between the black background and the clear brackets. The images were taken with $4800 \times 9600$ dpi optical resolution and enlargement up to 13 " $\times 19$ ". These samples were eventually observed visually from (x100) of image scale magnitude. They showed slices crumbs alveolar width and crusts thickness. Slices crumbs and crusts were visualized 24 hours after the baking process in order to have total firmness and freshness concentrations.

\section{Results and discussion}

\subsection{Dough gas bubbles volume rising and deformation during fermentation}

The physical properties of dough in bread making process include resistance to deformation, elasticity, extensibility and stickiness properties, but most of the desirable changes are related to the ability of the dough to retain gas bubbles during dough fermentation. They must also permit the uniform expansion of the dough under the influence of carbon dioxide $\left(\mathrm{CO}_{2}\right)$ gas from yeast fermentation during proof and baking processes (Veraverbeke \& Delcour, 2002). In order to ensure the quality of the bread, a study of gas bubbles development during fermentation becomes necessary to assess dough behavior during baking process. For that reason, the measurement of gaseous volume or pressure produced during dough fermentation was used to evaluate the initial dough viscoelasticity level.

Figures 1 and 2 show the variations of the volume of three types of maize-wheat dough versus time during their fermentation. Wheat dough is the control dough. Acceleration of each volume is observed versus time to reach a maximum of $590 \mathrm{~mL}$ for the volume of wheat dough enriched by GOX and $465 \mathrm{~mL}$ for the volume of wheat dough without GOX after $90 \mathrm{~min}$. The Figure 2 shows that volume of $\mathrm{CO}_{2}$ of the control dough supplemented with GOX was higher than the control dough without GOX due to the GOX catalytic activities. Several authors (Haarasilta et al., 1991; Gujral \& Rosell, 2004) indicated that the catalytic activities of glucose oxidase lead to the gas bubbles rising by strengthening the gluten matrix which could retain more gas bubbles during dough fermentation process. Their analysis revealed that the GOX supplementation to the wheat flour modified gluten proteins (gliadins and glutenins) leading to the formation of disulfide and nondisulfide crosslinks. According to Vemulapalli et al. (1998), Primo-Martín et al. (2003), Rosell et al. (2003), the basis of oxidation by GOX has been validated to be a result of the hydrogen peroxide produced. The resulting dough is more elastic and less viscous than the control dough without GOX. Comparing the results obtained for the dough samples containing maize flour, it is noticed that wheat-maize dough with GOX has higher values than maize dough without GOX (Figures 1 and 2). Overall, the differences between samples with / without GOX were not statistically significant. These results were probably influenced by maize flour and GOX catalytic reactions during mixing and fermentation. The scientific literature reported also that the losses of GOX activity during mixing and the improvement of the enzyme efficiency are more important with the time of

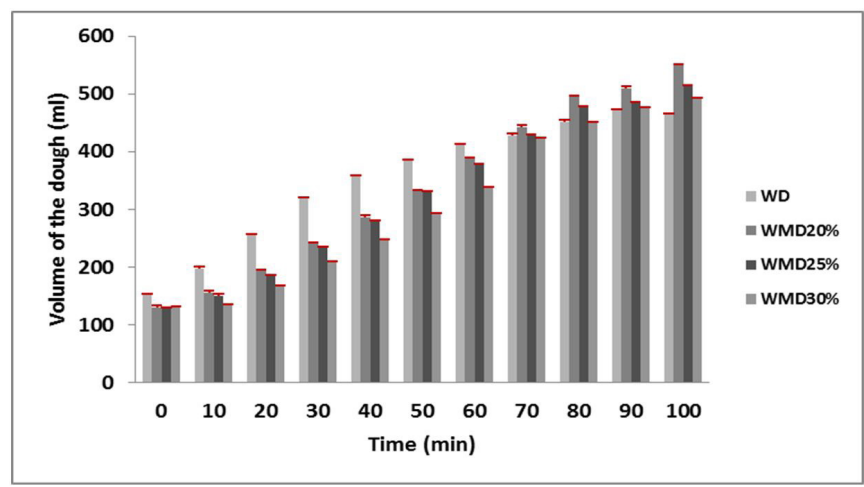

Figure 1. Dough samples volume versus time of fermentation process for different composite flours of maize and wheat without GOX addition; temperature $=25^{\circ} \mathrm{C}$. WD $=$ wheat dough; $\mathrm{WMD}=$ wheat dough containing maize; $\mathrm{GOX}=$ glucose oxidase.

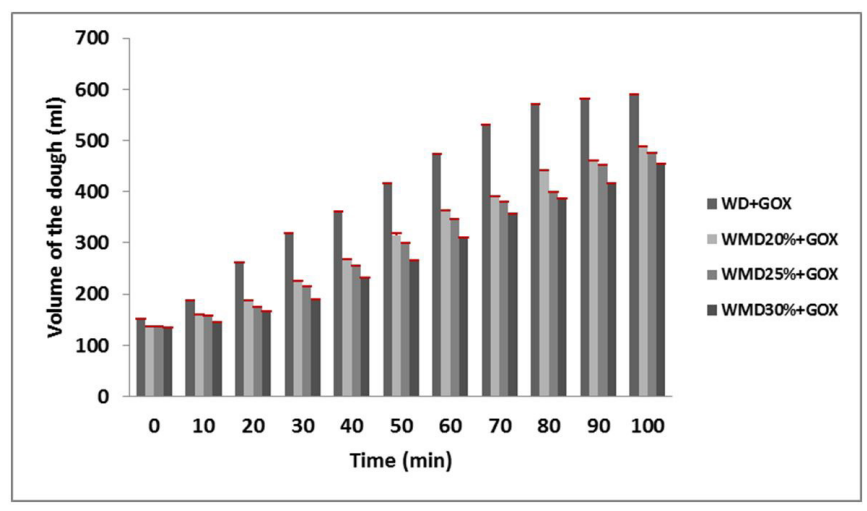

Figure 2. Dough samples volume versus time of fermentation process for different composite flours of maize and wheat with GOX addition; temperature $=25^{\circ} \mathrm{C}$. WD $=$ wheat dough; $\mathrm{WMD}=$ wheat dough containing maize; $\mathrm{GOX}=$ glucose oxidase.

fermentation process. Better results could be obtained in this case by reducing mixing time $(\sim 12-18 \mathrm{~min})$ and by prolonged fermentation (Caballero et al., 2007).

\subsection{Dough compression}

Dough samples compression test performed by the CT3 Texture Analyzer (Brookfield Engineering Laboratories, Inc. USA). The test is based on the theory that dough peak resistance and compressibility depends on the dough consistency level (Hibberd \& Parker, 1985; Kouassi-Koffi et al., 2016). These rheological theories were explored and exploited in this work to study the wheat-maize dough behavior versus stress amplitudes. Dough peak resistance to deformation as shown by maximum height within curves may be termed "dough strength". This behavior was much higher in case of dough samples without GOX addition than the ones enriched by GOX (Figures 3 and 4). 


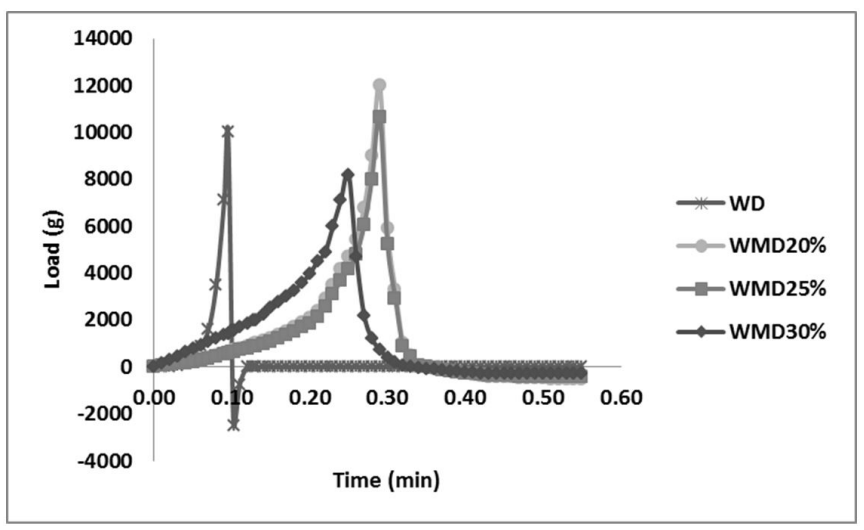

Figure 3. Variation of dough compression load versus time - dough samples without GOX, temperature $=25^{\circ} \mathrm{C}$. WD $=$ wheat dough; $\mathrm{WMD}=$ wheat dough containing maize flour; $\mathrm{GOX}=$ glucose oxidase.

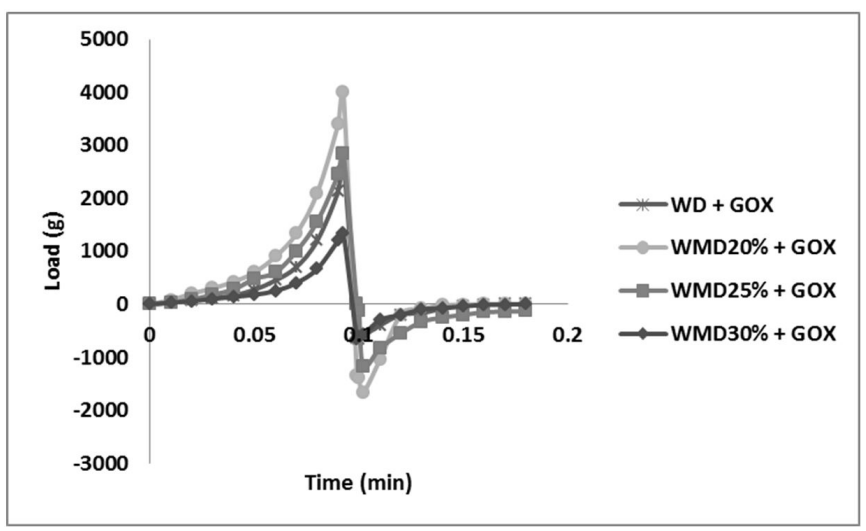

Figure 4. Variations of doughs compression load versus time - doughs with GOX supplementation, temperature $=25^{\circ} \mathrm{C}$. WD $=$ wheat dough; $\mathrm{WMD}=$ wheat dough containing maize flour; $\mathrm{GOX}=$ glucose oxidase.

\subsection{Bread weight and volume measurement}

The bread crumb alveolar structure highly influences the textural characteristics of bakery products, being an important quality parameter for bread weight and volume; thus, the high quality bread will show a high number of crumb alveoli (Hibberd \& Parker, 1985). After baking, the variations of bread weight and volume versus time are linked to bread density (Zghal et al., 1999). In order to know how modifications of the bread dough cellular structure by GOX and maize flour can influence the final bread physical appearance, the weight and volume test were performed. The bread weight and volume are shown that the density of the dough enriched by GOX $(0.23 \pm 0.01 \mathrm{~g} / \mathrm{mL})$ is more stimulating than the witness dough $(0.28 \pm 0.03 \mathrm{~g} / \mathrm{mL})$ in a ratio of $82.14 \pm 0.01 \%$. The wheat-maize bread with GOX density $(0.19 \pm 0.01 \mathrm{~g} / \mathrm{mL})$ is also higher than the one of wheat-maize bread without GOX $(0.24 \pm 0.01 \mathrm{~g} / \mathrm{mL})$ in a ratio of $80 \%$. The density of bread samples might be also dependent to water loss due to the temperature rising $\left(25 \rightarrow 180^{\circ} \mathrm{C}\right)$ and proteins catalytic reactions (GOX supplement) during the baking process confirmed by Moore \& Hoseney (1985), but also because of maize flour addition (absence of gluten proteins). Several complex proteins reactions are disrupted in the dough with the addition of GOX determining the reorganization of the final bread structure and texture (Kouassi-Koffi et al., 2017).

The weight and volume of the bread (wheat and Wheat-Maize) with GOX supplement are higher than the control bread (wheat and Wheat-Maize) without GOX due to initial catalytic reactions of enzymes on dough which improve its alveolar structure. These reactions allowed the reorganization of proteins network from the mixing to baking via kneading and fermentation processes (Kouassi-Koffi et al., 2017), as well as obtaining voluminous and airy bread samples, the results being in accordance with the texture of baking products described by Vemulapalli et al. (1998). They had demonstrated also that physical property of bread such as density $(\mathrm{w} / \mathrm{v})$ which might be related to quantity and quality of gluten and thus to the rheological properties of dough, depend of the initial cellular structure of the dough. This reorganization of dough macrostructure is dependent on the proteins networks which were modified partially by GOX addition to the flour at the early steps of breadmaking (Kouassi-Koffi et al., 2017). However, in the current work, these reactions are probably inhibited by the quantity of maize flour and their protein characteristics.

\subsection{Bread texture}

Peak resistance, area of work and extensibility of bread crumb deformation are defined as indicators of bread firmness and freshness. These parameters could be influenced by the dough viscoelasticity level (Hibberd \& Parker, 1985). In order to know how bread dough viscoelasticity level increasing by the GOX addition could influence bread quality, the resistance and extensibility tests of bread to deformation were performed (Figures 5 and 6).

Bread crumb peak resistance to deformation, as shown by maximum height within curves, can be termed as "crumb strength" and indicator of bread quality. Overall, in Figures 5 and 6 it might be noticed that the bread crumbs with GOX were presenting higher load values than the bread crumbs without GOX. Maximum load value was $12000 \mathrm{~g}$ for wheat bread with $20 \%$ maize flour addition without GOX, a similar value being registered for the GOX containing samples. According to these results, it can be said that glucose oxidase supplementation does not provide the expected changes on dough and respectively, on bread crumbs. These compression tests determine the bread sample firmness properties and its characteristic evaluations. They generate bread crumb strength indicating its freshness quality. The results obtained for crumb showed that the wheat-maize bread samples with GOX have better resistance, strength and extensibility than breads without GOX, although small differences between obtained values were noticed. 


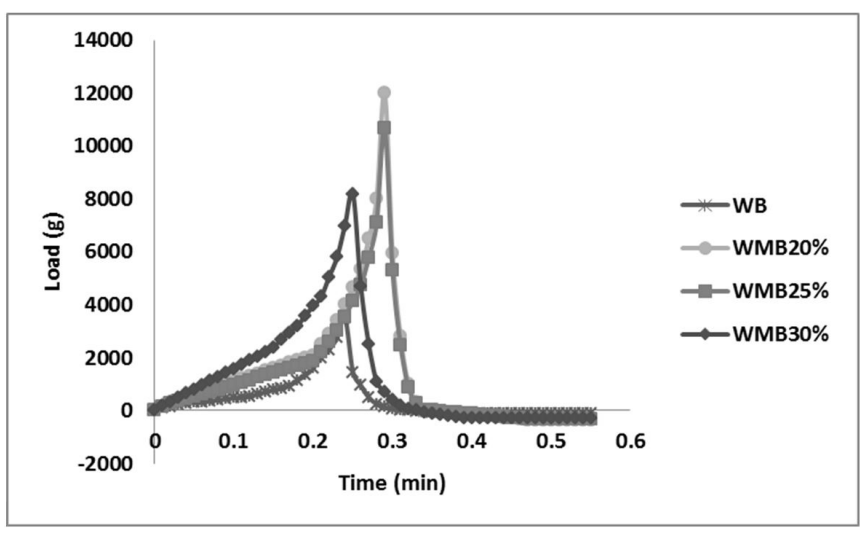

Figure 5. Variations of bread crumbs compression load versus time. Bread crumbs without GOX, temperature $=25^{\circ} \mathrm{C}$. WB $=$ wheat bread; $\mathrm{WMB}=$ wheat bread with maize addition; $\mathrm{GOX}=$ glucose oxidase.

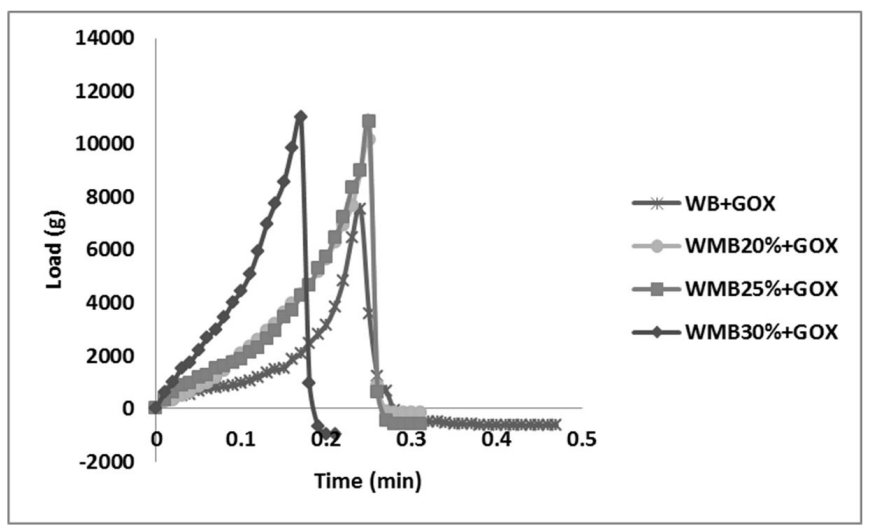

Figure 6. Variations of bread crumbs compression load versus time. Bread crumbs with GOX addition, temperature $=25^{\circ} \mathrm{C}$. WB $=$ wheat bread; $\mathrm{WMB}=$ wheat bread with maize addition; $\mathrm{GOX}=$ glucose oxidase.

\subsection{Bread crumb physical properties}

Textural characteristics are key criterions of consumer's choices. They can be observed and smelled directly. Crumb freshness is directly associated to its specific structure and then to the mechanical properties of the cell walls that can form the air cells in bread (Liu \& Scanlon, 2003, 2004). According to Liu \& Scanlon $(2003,2004)$ these characteristics of bread give indications of its digestive quality. In order to know how the physical properties of the bread crumb can improve basic knowledge, visual characterization of slices bread by images pickup was done. Figure 7 shows images of slices crumbs alveolar width and crusts thickness for both samples breads. The crumbs enriched with GOX showed almost the same values of alveoli and diameters with crumbs without GOX supplementation; also, other authors did not observe great differences in crumb texture or increased volume when using GOX (Vemulapalli et al., 1998; Rasiah et al., 2005; Caballero et al., 2007). It means that the activity of added enzyme (glucose oxidase) was influenced by maize flour, which has a different chemical composition in comparison with wheat flour, especially due to the different content of proteins; around half of maize flour proteins are made up of zein (Mejía, 2003), but wheat flour proteins consist mainly in gliadins and glutenins (Wieser, 2007). These are sustained by results obtained by Gujral \& Rosell (2004) on rice flour bread; the study reported that GOX modified the rice flour proteins by lowering the thiol and amino group concentration, fact confirmed by the changes observed in the free zone capillary electrophoregrams of the rice glutelins. Also, it is possible that by maize flour addition an enhancement of arabinoxylan content occurred in the wheat-maize dough. Maize arabinose-to-xylose ratio range of 0.6 to 0.7 , very close to the wheat endosperm arabinoxylan (Agger et al., 2010). Pentosans can indirectly effect gluten formation by competing for water. Pentosan-modifying enzymes can then act by reducing the water-binding capacity of pentosans thus inducing water redistribution. Another indirect effect of pentosans could be caused by their ability to form a network limiting the movement of glutenin proteins toward a larger aggregate (Dagdelen \& Gocmen, 2007). For the breakdown of this pentosan network, a pentosanase is needed.
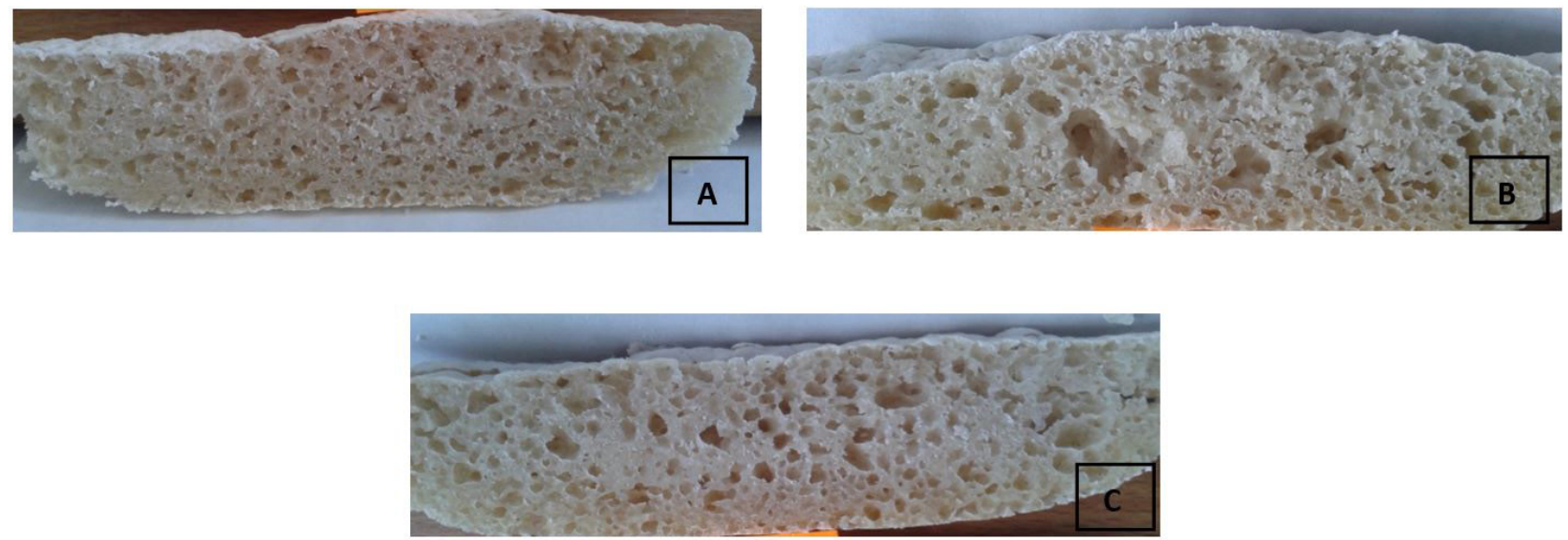

Figure 7. Examples of crust alveolar physical appearance for wheat-maize bread crumb enriched with glucose oxidase containing $20 \%$ (A), $25 \%$ (B) and $30 \%$ (C) maize flour. 


\section{Conclusions}

Wheat bread rheological properties studies allow obtaining the description of its hardness and freshness characteristics. These properties depend mainly on the dough consistency, flow and strain hardening behaviors. These properties are influenced in a good way by GOX and maize flour addition, probably due to GOX and maize flour proteins interactions. The values of load at $20 \%$ maize flour supplementation were higher almost every time, meaning that a $20 \%$ maize flour induced a hardening behavior to the dough, and respectively, to the end product, because mainly of the protein content. The values of load at $25 \%$ and $30 \%$ maize flour supplementation were also accepted results because of the quality of the final products as compared to initial wheat bread.

\section{Acknowledgements}

We thank to Romanian Government and Francophone University Agency (AUF) who supported partially this research through the Eugen Ionesco Postdoctoral scholarship program. We thank also the European Social Fund (Human Resources Development Operational Program 2007-2013, project no. POSDRU/159/1.5/S/132765). This work was also supported by a grant of the Romanian National Authority for Scientific Research and Innovation, CNCS/CCCDI-UEFISCDI, project number PN-III-P2-2.1-BG-2016-0122 within PNCDI III.

\section{References}

Agger, J., Viksø-Nielsen, A., \& Meyer, A. S. (2010). Enzymatic xylose release from pretreated corn bran arabinoxylan: differential effects of deacetylation and deferuloylation on insoluble and soluble substrate fractions. Journal of Agricultural and Food Chemistry, 58(10), 61416148. http://dx.doi.org/10.1021/jf100633f. PMid:20411987.

American Association of Cereal Chemists - AACC. (1998). Approved methods of the American Association of Cereal Chemists: method 1005 guidelines for measurement of volume by rapeseed displacement (9th ed.). St. Paul: AACC.

Banu, I., Stoenescu, G., Ionescu, V., \& Aprodu, I. (2011). Estimation of the baking quality of wheat flours based on rheological parameters of the mixolab curve. Czech Journal of Food Sciences, 29(1), 35-44. http://dx.doi.org/10.17221/40/2009-CJFS.

Bilgiçli, N., Kara, M., Elgün, A., Ertaş, N., \& Demir, M. K. (2006). Determination of technologic and sensory properties of cookies prepared with corn flour. Journal of Food Agriculture and Environment, 4(2), 109-111.

Bonet, A., Rosell, C. M., Caballero, P. A., Gómez, M., Pérez-Munuera, I., \& Lluch, M. A. (2006). Glucose oxidase effect on dough rheology and bread quality: a study from macroscopic to molecular level. Food Chemistry, 99(2), 408-415. http://dx.doi.org/10.1016/j. foodchem.2005.07.043.

Caballero, P. A., Bonet, A., Rosell, C. M., \& Gómez, M. (2005). Effect of microbial transglutaminase on the rheological and thermal properties of insect damaged wheat flour. Journal of Cereal Science, 42(1), 93-100. http://dx.doi.org/10.1016/j.jcs.2004.12.006.

Caballero, P. A., Gómez, M., \& Rosell, C. M. (2007). Improvement of dough rheology, bread quality and bread shelf-life by enzymes combination. Journal of Food Engineering, 81(1), 42-53. http://dx.doi. org/10.1016/j.jfoodeng.2006.10.007.
Dagdelen, A. F., \& Gocmen, D. (2007). Effects of glucose oxidase, hemicellulase and ascorbic acid on dough and bread quality. Journal of Food Quality, 30(6), 1009-1022. http://dx.doi.org/10.1111/j.17454557.2007.00156.x.

Day, L., Augustin, M. A., Batey, I. L., \& Wrigley, C. W. (2006). Wheatgluten uses and industry needs. Trends in Food Science \& Technology, 17(2), 82-90. http://dx.doi.org/10.1016/j.tifs.2005.10.003.

Decamps, K., Joye, I. J., Courtin, C. M., \& Delcour, J. A. (2012). Glucose and pyranose oxidase improve bread dough stability. Journal of Cereal Science, 55(3), 380-384. http://dx.doi.org/10.1016/j.jcs.2012.01.007.

Dewettinck, K., Van Bockstaele, F., Kühne, B., Van de Walle, D., Courtens, T., \& Gellynck, X. (2008). Nutritional value of bread: influence of processing, food interaction and consumer perception- Review. Journal of Cereal Science, 48(2), 243-257. http://dx.doi.org/10.1016/j. jcs.2008.01.003.

Figoni, P. I. (2003). Bleaching and maturing agents: how baking works: exploring the fundamentals of baking science (1st ed., pp. 71). Hoboken: Wiley.

Food and Drug Administration - FDA, Center for Food Safety and Applied Nutrition - CFSAN. (2002). Agency Response Letter: GRAS Notice $n^{\circ}$ GRN 000106, Agency Response Letter: GRAS Notice $n^{\circ}$ GRN 000089. Silver Spring: FDA.

Gujral, H. S., \& Rosell, C. M. (2004). Improvement of the breadmaking quality of rice flour by glucose oxidase. Food Research International, 37(1), 75-81. http://dx.doi.org/10.1016/j.foodres.2003.08.001.

Gwirtz, J. A., \& Garcia-Casal, M. N. (2014). Processing maize flour and corn meal food products. Annals of the New York Academy of Sciences, 1312(1), 66-75. http://dx.doi.org/10.1111/nyas.12299. PMid:24329576.

Haarasilta, S., Pullinen, T., Vaisanen, S., \& Tammersalo-Karsten, I. (1991). Enzyme product and method of improving the properties of dough and the quality of bread. Patent No. 4990 343. Alexandria: The United States Patent and Trademark Office.

Hanft, F., \& Koehler, P. (2006). Studies on the effect of glucose oxidase in bread making. Journal of Food Science of Food and Agriculture, 86(11), 1699-1704. http://dx.doi.org/10.1002/jsfa.2455.

Hibberd, G. E., \& Parker, N. S. (1985). Measurements of the compression properties of bread crumb. Journal of Texture Studies, 16(1), 97-110. http://dx.doi.org/10.1111/j.1745-4603.1985.tb00682.x.

Kerman, F. K. P., Salehifar, M., \& Mirzaei, M. (2014). Investigation of the possibility of glucose oxidase enzyme in combination of ascorbic acid for improving quality of frozen dough and its resulted bread. European Journal of Experimental Biology, 4(3), 716-721.

Kouassi-Koffi, J. D., Kone, F. M. T., Gonnety, T. J., \& Assemand, E. (2017). Wheat bread firmness and freshness properties dependence on dough flow and hardening behavior. International Journal of Biology, Pharmacy and Allied Sciences, 6(5), 880-900.

Kouassi-Koffi, J. D., Kouassi, K. H., Yapi, A. Y. D. P., Ahi, A. P., Muresan, V., Mudura, E., \& Asseman, E. (2016). Wheat Bread dough rheological properties study dependence on the dough viscoelasticity level. International Journal of Recent Biotechnology, 4(1), 1-12.

Liu, Z., \& Scanlon, M. G. (2003). Predicting mechanical properties of bread crumb. Food and Bioproducts Processing: Transactions of Institute of Chemical Engineers Part C, 81(3), 224-238. http://dx.doi. org/10.1205/096030803322437992.

Liu, Z., \& Scanlon, M. G. (2004). Revisiting crumb texture evaluation methods: tension, compression. Cereal Foods World, 49(2), 76-82.

Macosko, C. W. (1994). Rheology: principles, measurements, and applications (Vol. 1, pp. 181-235). New York: VCH Publishers. 
Mejía, D. (2003). MAIZE: post-harvest operation. Rome: AGST/FAO. Retrieved from http://www.fao.org/fileadmin/user_upload/inpho/ docs/Post_Harvest_Compendium_-_MAIZE.pdf

Moore, M. M., \& Chen, T. (2006). Mutagenicity of bromate: Implications for cancer risk assessment. Toxicology, 221(2-3), 190-196. http:// dx.doi.org/10.1016/j.tox.2005.12.018. PMid:16460860.

Moore, W. R., \& Hoseney, R. C. (1985). The leavening of bread dough. Cereal Foods World, 30, 791-792.

Primo-Martín, C., Valera, R., \& Martínez-Anaya, M. A. (2003). Effect of pentosanase and oxidases on the characteristics of doughs and the glutenin macropolymer (GMP). Journal of Agricultural and Food Chemistry, 51(16), 4673-4679. http://dx.doi.org/10.1021/jf0257695. PMid:14705895.

Rasiah, I. A., Sutton, K. H., Low, F. L., Lin, H. M., \& Gerrard, J. A. (2005). Crosslinking of wheat dough proteins by glucose oxidase and the resulting effects on bread and crissants. Food Chemistry, 89(3), 325-332. http://dx.doi.org/10.1016/j.foodchem.2004.02.052.

Rose, D. J., Inglett, G. E., \& Liu, S. X. (2010). Utilisation of corn (Zea mays) bran and corn fiber in the production of food components. Journal of the Science of Food and Agriculture, 90(6), 915-924. PMid:20355130.

Rosell, C. M., Wang, S., Aja, S., Bean, S., \& Lookhart, G. (2003). Wheat flour proteins as affected by transglutaminase and glucose oxidase. Cereal Chemistry, 80(1), 52-55. http://dx.doi.org/10.1094/ CCHEM.2003.80.1.52.

Secor, R. B., Schunk, P. R., Hunter, T. B., Stitt, T. F., Macosko, C. W., \& Scriven, L. E. (1989). experimental uncertainties in extensional rheometry of liquids by fiber drawing. Journal of Rheology, 33(8), 1329-1358. http://dx.doi.org/10.1122/1.550009.

Sievert, D., Hoseney, R. C., \& Delcour, J. A. (2007). Bread and other baked products. In Wiley-VCH (Ed.), Ullmann's Encyclopedia of Industrial Chemistry. Weinheim: Wiley-VCH Verlag. http://dx.doi. org/10.1002/14356007.a04_331.pub2.
Singh, J., \& Verma, N. (2013). Glucose oxidase from Aspergillus niger: production, characterization and immobilization for glucose oxidation. Advances in Applied Science Research, 4(3), 250-257.

Steffolani, M. E., Ribotta, P. D., Pérez, G. T., \& León, A. E. (2010). Effect of glucose oxidase, transglutaminase, and pentosanase on wheat proteins: relationship with dough properties and bread-making quality. Journal of Cereal Science, 51(3), 366-373. http://dx.doi. org/10.1016/j.jcs.2010.01.010.

Steffolani, M. E., Ribotta, P. D., Pérez, G. T., \& León, A. E. (2012). Combinations of glucose oxidase, alpha-amylase and xylanase affect dough properties and bread quality. International Journal of Food Science \& Technology, 47(3), 525-534. http://dx.doi.org/10.1111/j.13652621.2011.02873.x.

Vemulapalli, V., \& Hoseney, R. C. (1998). Glucose oxidase effects on gluten and water solubles. Cereal Chemistry, 75(6), 859-862. http:// dx.doi.org/10.1094/CCHEM.1998.75.6.859.

Vemulapalli, V., Miller, K. A., \& Hoseney, R. C. (1998). Glucose oxidase in bread making systems. Cereal Chemistry, 75(4), 439-442. http:// dx.doi.org/10.1094/CCHEM.1998.75.4.439.

Veraverbeke, W. S., \& Delcour, J. A. (2002). Wheat protein composition and properties of wheat glutenin in relation to breadmaking functionality. Critical Reviews in Food Science and Nutrition, 42(3), 179-208. http:// dx.doi.org/10.1080/10408690290825510. PMid:12058979.

Wieser, H. (2007). Chemistry of gluten proteins. Food Microbiology, 24(2), 115-119. http://dx.doi.org/10.1016/j.fm.2006.07.004. PMid:17008153.

Wong, C. M., Wong, K. H., \& Chen, X. D. (2008). Glucose oxidase: natural occurrence, function, properties and industrial applications. Applied Microbiology and Biotechnology, 78(6), 927-938. http://dx.doi. org/10.1007/s00253-008-1407-4. PMid:18330562.

Zghal, M. C., Scanlon, M. G., \& Sapirstein, H. D. (1999). Prediction of bread crumb density by digital image analysis. Cereal Chemistry, 76(5), 734-742. http://dx.doi.org/10.1094/CCHEM.1999.76.5.734. 